Article

\title{
Biocontrol of Penicillium nordicum Growth and Ochratoxin A Production by Native Yeasts of Dry Cured Ham
}

\author{
Roberta Virgili ${ }^{1}{ }^{*}$, Nicoletta Simoncini ${ }^{1}$, Tania Toscani ${ }^{1}$, Marco Camardo Leggieri ${ }^{2}$, \\ Silvia Formenti ${ }^{2}$ and Paola Battilani ${ }^{2}$
}

1 Stazione Sperimentale per l'Industria delle Conserve Alimentari, V.le F. Tanara, 31/A, Parma 43121, Italy; E-Mails: nicoletta.simoncini@ssica.it (N.S.); tania.toscani@ssica.it (T.T.)

2 Institute of Entomology and Plant Pathology, Università Cattolica del Sacro Cuore, Via Emilia Parmense, 84, Piacenza I29100, Italy;

E-Mails: marco.camardoleggieri@unicatt.it (M.C.L.); silvia.formenti@unicatt.it (S.F.); paola.battilani@unicatt.it (P.B.)

* Author to whom correspondence should be addressed; E-Mail: roberta.virgili@ssica.it; Tel.: +39-0521-795249; Fax: +39-0521-771829.

Received: 28 December 2011; in revised form: 18 January 2012 / Accepted: 20 January 2012 / Published: 1 February 2012

\begin{abstract}
Twelve yeast strains isolated from the surface of Italian typical dry-cured hams, belonging to D. hansenii, D. maramus, C. famata, C. zeylanoides and H. burtonii species, and previously selected for their ability to grow in dry-cured ham-like substrates, were screened for antagonistic activity against a toxigenic strain of $P$. nordicum and inhibition of ochratoxin A (OTA) biosynthesis. On average, yeast inhibitory activity was lowered by increasing fungal inoculum and enhanced by $\mathrm{NaCl}$ presence. In the assay conditions, $H$. burtonii and C. zeylanoides were the most effective, both in inhibiting P. nordicum growth and OTA production. D. hansenii was the species with the lowest inhibitory activity, especially in the absence of salt. OTA production dropped from the range $<$ LOD $-5000 \mathrm{ppb}$ in $P$. nordicum control plates to the range $<$ LOD $-200 \mathrm{ppb}$ in yeast-added plates. OTA production increased in the presence of $\mathrm{NaCl}$ in $P$. nordicum control plates, while salt enhanced inhibition against OTA production in yeast-added plates.
\end{abstract}

Keywords: antagonistic yeasts; Penicillium nordicum; ochratoxin A; $\mathrm{NaCl}$; dry-cured meat product 


\section{Introduction}

The mycete populations (yeasts and moulds) colonizing the surface layers of dry-cured meat products during maturation have been regarded as positively contributing to the chemosensory properties of final outcome, by means of oxidation prevention and generation of volatile compounds enhancing aroma $[1,2]$. In the case of dry-cured ham, yeasts form a film on ham surface during early and intermediate processing steps, while moulds can develop fungal mycelium even after yeast growth [3].

Among moulds isolated from dry-cured meat facilities and products, Penicillia were largely dominant, and the contamination levels have been found to be associated to the environmental conditions of ripening rooms [4,5], geographic area of production [6-8] and seasonality [9]. Among Penicillia, P. nordicum, a toxigenic contaminant of protein-rich food [10], was isolated from air and products of dry-curing plants [5,9]. Several $P$. nordicum isolates proved to be important producers of ochratoxin A (OTA), a mycotoxin classified by the International Agency for the Research on Cancer (IARC) as a possible human carcinogen, suspected to be involved in nephropathies and urothelial tract tumours [11]. OTA was detected in substrates contaminated by P. nordicum [12], including dry-cured pork samples $[13,14]$. Currently, the appropriate setting of environmental conditions (temperature, relative humidity and air circulation), is the only accepted tool to prevent the uncontrolled growth of $P$. nordicum inside dry-curing plants.

Biological control of $P$. nordicum contamination based on microbial antagonists can be investigated as a possible way to improve food safety without affecting sensory quality and properties of typical dry-cured meat products. As a rule, during manufacturing a wild yeast population spontaneously grows on dry-cured ham surface, achieving different counts according to processing stage and type [15,16]. Yeast species isolated from ham during processing mainly belonged to genera Debaryomyces, Candida and less frequently to Cryptococcus, Rhodotorula and Rhodosporidium [15-17]. Native yeasts more frequently isolated from dry-cured hams were regarded as non-pathogenic with the exception of Candida zeylanoydes [18] and proved to be able of growing to high populations in conditions of temperature, $\mathrm{pH}$, moisture, $\mathrm{a}_{\mathrm{w}}$ and salt typical of dry-cured ham surface [1,19]. Recently, selected yeasts were added to dry-cured meat products as starter cultures to enrich the volatile compound profile $[2,20]$. The antagonistic potential of yeasts against Penicillia has been considered for different food matrixes, such as cereals [21,22], coffee [23], fruits [24] or fermented food like wine [25], cheese and yogurt [26]. Recent studies report the use of antagonistic yeasts as surface starter cultures inhibiting fungal growth also in dry-cured meat products [8,27].

The aim of this work is to evaluate in vitro the ability of selected yeasts isolated from dry-cured ham surface to compete with $P$. nordicum and to inhibit OTA accumulation in the perspective of using them as surface starter cultures.

\section{Materials and Methods}

\subsection{Selection and Identification of Yeast Species}

Tested yeast strains $(n=12)$ were selected from a total of 270 isolated from dry-cured ham during the maturing process [15] and stored in the collection of Stazione Sperimentale per l'Industria delle Conserve Alimentari (Parma, Italy). 
The yeast strains, selected in a previous study for their potential competition against $P$. nordicum and ability to grow in a dry-cured ham-like substrate [19], were purified by repeated cultivation on Malt Extract Agar (MEA, Oxoid) and maintained at $4{ }^{\circ} \mathrm{C}$ on Yeast Peptone Dextrose agar (YPD yeast extract, $10 \mathrm{~g}$; peptone, $20 \mathrm{~g}$; glucose, $20 \mathrm{~g}$; agar, $15 \mathrm{~g}$ and deionized water, $1000 \mathrm{~mL}$ ) before use. Yeast strains were phenotypically identified as Candida zeylanoides $(n=2)$, Hyphopichia burtonii $(n=2)$, Debaryomyces hansenii $(n=2)$, Debaryomyces maramus $(n=3)$ and Candida famata $(n=3)$, by means of the Biolog system (Biolog Inc., Hayward, CA, USA). Furthermore, yeast cells from the pure cultures of the above-mentioned strains underwent genetic identification by sequencing the D1/D2 domain of 26rRNA encoding gene [28]. The strains phenotypically identified as belonging to $C$. zeylanoides and $H$. burtonii species were confirmed by genetic system, while the remaining strains were genotyped as D. hansenii.

\subsection{Preparation of Yeast Inocula}

Yeast cultures were grown in $10 \mathrm{~mL}$ Malt Extract Broth (MEB, Oxoid) at $25{ }^{\circ} \mathrm{C}$ for $48 \mathrm{~h}$. Suspensions were prepared by inoculating $25 \mathrm{~mL}$ of YPD broth with a loop full of cells and incubating on a rotary shaker $(180 \mathrm{rpm})$ at $28{ }^{\circ} \mathrm{C}$ for $24 \mathrm{~h}$. The density of yeast cultures was determined spectrophotometrically by measuring their optical density at $600 \mathrm{~nm}$.

\subsection{Preparation of P. nordicum Inocula}

An ochratoxin A producing strain of $P$. nordicum isolated from cured pork meat in a previous research [5] and identified at molecular level [29], was used in this study; the strain was stored in the fungal collection of the Institute of Entomology and Plant Pathology, Università Cattolica del Sacro Cuore in Piacenza (code MPVP) and of the Federal Research Centre for Nutrition and Food, in Karlsruhe (Germany; code BFE 838).

The strain has been grown on Petri dishes $(9 \mathrm{~cm}$ diameter) with Czapek Yeast extract Agar (CYA: sucrose $30.0 \mathrm{~g}$; yeast extract $5.0 \mathrm{~g}$; sodium nitrate $3.0 \mathrm{~g}$; dipotassium phosphate $1.0 \mathrm{~g}$; magnesium sulfate $0.5 \mathrm{~g}$; potassium chloride $0.5 \mathrm{~g}$; agar $15 \mathrm{~g}$; ferrous sulfate $10 \mathrm{mg}$ and deionized water, $1000 \mathrm{~mL}$ ) and incubated at $25{ }^{\circ} \mathrm{C}$ for 7 days. At the end of incubation, $10 \mathrm{~mL}$ of sterilized water was added to the culture surface and it was gently scraped to remove most of the conidia for the inoculum preparation. The obtained conidial suspension was adjusted to $10^{2}, 10^{4}, 10^{6}$ conidia/mL using a hemocytometer.

\subsection{Inhibition Assay of P. nordicum by Yeast Strains}

The assay was carried out by means of the test described by Bleve et al. [30] modified as follows.

Experiments were performed on YPD agar medium adjusted to $\mathrm{pH}$ 6, with and without the addition of sodium chloride (3\%). A top agar was prepared by mixing $6 \mathrm{~mL}$ of YPD with $0.7 \%$ agar and $1 \mathrm{~mL}$ of yeast suspension containing $10^{8}$ cells to obtain a thick, continuous layer on plate surface. This suspension was distributed into Petri plates containing $15 \mathrm{~mL}$ of YPD agar media. Then, three $10 \mu \mathrm{L}$ portions for each $P$. nordicum suspension corresponding to $10^{2}, 10^{4}, 10^{6}$ conidia/mL, were separately spotted on each plate and incubated at $20^{\circ} \mathrm{C}$. The inocula of $P$. nordicum were carried out at the same 
time (co-cultured) and four days after the yeast-media preparation (delayed). Two replicate experiments for each condition were performed. Culture media (YPD and YPD $+3 \% \mathrm{NaCl}$ ) plates not inoculated with yeasts were included as control.

Fungal growth was expressed as the average measure $(\mathrm{mm})$ of two orthogonal diameters/colony after 14 days of incubation. The inhibitory activity was calculated by the Equation (1) reported by Lima et al. [31]:

$$
\% \text { Inibitory activity }=\frac{\text { fungal growth in control plate }- \text { fungal growth in treated plate }) \times 100}{\text { fungal growth in controled plate }}
$$

\subsection{OTA Production by P. nordicum}

Control and yeast-added plates inoculated with $P$. nordicum were analyzed for OTA content after 14 days of incubation. OTA was measured according to the method of Bragulat et al. [32], modified as follows. The content of each plate, including fungal colony and medium, was transferred in a flask with a screw cap, added whit methanol 1:2 (w/v ratio), and left in dark extraction for one hour, shaking each 15 minutes. After filtration, $100 \mu \mathrm{L}$ of extract was diluted according to Toscani et al. [33], analyzing the final solutions by HPLC-FLD quantitative method. It was performed with a C18 column $\left(\right.$ Waters XTerra ${ }^{\circledR}, 250 \times 2.1 \mathrm{~mm}, 3 \mu \mathrm{m}$ ) on a Agilent 1100 chromatographic system (Agilent Technologies, USA) under isocratic condition at room temperature, with an aqueous $\mathrm{NH}_{3} / \mathrm{NH}_{4} \mathrm{Cl}$ (20 mM, pH 9.8): $\mathrm{CH}_{3} \mathrm{CN}=85: 15 \mathrm{v} / \mathrm{v}$ mobile phase; the flow was $0.2 \mathrm{~mL} / \mathrm{min}$ and the injected volume was $20 \mu \mathrm{L}$. The FLD detection was obtained by means of an Agilent 1100 Fluorescence Detector (Agilent Technologies, USA) $(\lambda \mathrm{ex}=380 \mathrm{~nm}, \lambda \mathrm{em}=440 \mathrm{~nm})$. OTA has been expressed as $\mathrm{ng} / \mathrm{g}$ medium. The limit of detection (LOD) and the limit of quantification (LOQ) in plates were $0.2 \mathrm{ppb}$ and $0.6 \mathrm{ppb}$ respectively.

\subsection{OTA Recovery in Yeast Treated Plates}

Culture media (YPD and YPD +3\% NaCl) were spiked with $500 \mathrm{ppb}$ OTA/plate; then, the top agar was added with $1 \mathrm{~mL}$ of yeast suspension containing $10^{8}$ cells in the case of test plates and with $1 \mathrm{~mL}$ of physiological solution in the case of control plates. Plates were incubated at $20{ }^{\circ} \mathrm{C}$ for 14 days and stored at $20^{\circ} \mathrm{C}$ before OTA analysis.

\subsection{Statistical Analysis}

Data analysis was carried out using the SPSS software package (SPSS 15.0, SPSS Inc. Chicago, IL, USA). Data of yeast inhibitory activity and OTA production were inspected for normal distribution using the procedures Frequencies (mean, median, Skewness and Curtosis tests) and Kolmogorov-Smirnov test. Least Square Means (LSM) of yeast inhibitory activity vs. P. nordicum were estimated by means of General Linear Model (GLM) procedure for the main effects "yeast species", "salt presence", "fungal inoculum level" and their two-way interactions; the Bonferroni $t$-test was used to statistically separate LSM when $P<0.05$. Percentile distribution of OTA amount in yeast-added- and control plates inoculated with $P$. nordicum, was analyzed using non parametric test ( $\chi 2$ test), according to yeast species. 


\section{Results}

\subsection{Yeast Inhibition Activity Against P. nordicum}

The biocontrol test was performed using 12 yeast strains selected among a far exceeding number isolated from dry-cured hams [15]. Yeast selection was made according to their capability of growing in meat model substrates simulating $\mathrm{a}_{\mathrm{w}}$ values, $\mathrm{NaCl}$ content, $\mathrm{pH}$ and nutrients of dry-cured ham surface, and exerting in vitro competition potential against $P$. nordicum [19].

For each phenotypic species (D. hansenii, D. maramus, C. zeylanoides, C. famata, H. burtonii), at least two strains were included in the biocontrol assays, and tested strains caused a visible growth reduction of $P$. nordicum after 14 days of incubation, as displayed in Figure 1. Diameters of fungal colonies were reported in Table 1, both for control- (37-44 $\mathrm{mm}$ range) and yeast-added plates (5-11 mm range): differences in P. nordicum inoculum were related to colony diameters, because the larger colonies at 14 days of incubation corresponded to higher inocula.

Figure 1. Growth of $P$. nordicum $\left(10^{4}\right.$ conidia/mL) on Yeast Peptone Dextrose (YPD) and YPD $+3 \% \mathrm{NaCl}$ agar (control) for 7 days at $20{ }^{\circ} \mathrm{C}$ compared to the growth of $P$. nordicum $\left(10^{2}, 10^{4}, 10^{6}\right.$ conidia/mL) on YPD and YPD $+3 \% \mathrm{NaCl}$ agar containing $10^{8} \mathrm{cfu} / \mathrm{mL}$ of selected yeast (yeast-added plates).

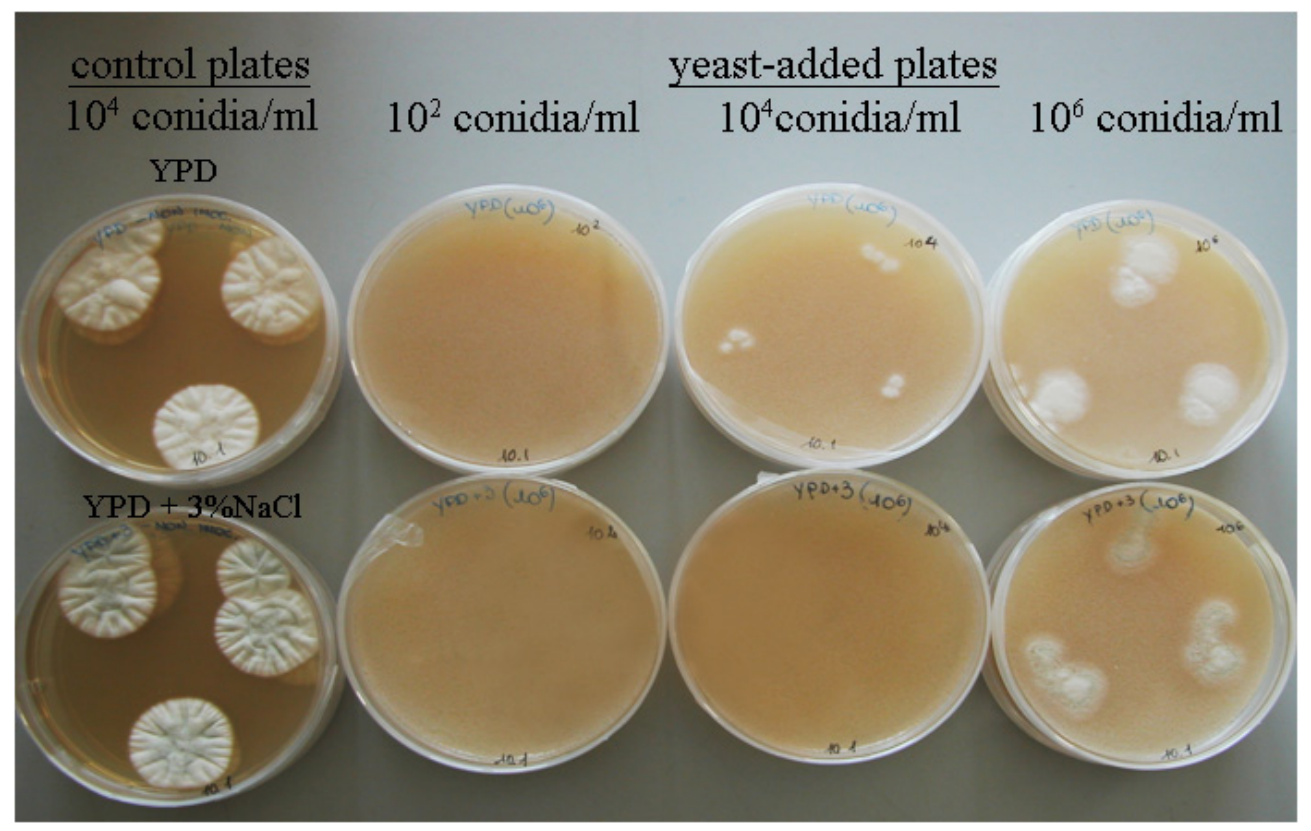


Table 1. Diameters (mm) of Penicillium nordicum colonies in control (C) and yeast-added (Y) plates $\left(10^{8} \mathrm{cfu} / \mathrm{mL}\right)$ with Yeast Peptone Dextrose agar after 14 days of incubation at $20^{\circ} \mathrm{C}$. Plates were inoculated with $P$. nordicum at $10^{2}, 10^{4}$ and $10^{6}$ conidia $/ \mathrm{mL}$.

\begin{tabular}{lcccc}
\hline & & \multicolumn{3}{c}{$\boldsymbol{P . ~ n o r d i c u m}^{\mathbf{a}}$} \\
\cline { 2 - 5 } Yeast species & Test & $\mathbf{1 0}^{\mathbf{2}}$ & $\mathbf{1 0}^{\mathbf{4}}$ & $\mathbf{1 0}^{\mathbf{6}}$ \\
\hline \multirow{2}{*}{ D. hansenii } & $\mathrm{C}$ & $35.5 \pm 2.0$ & $41.6 \pm 2.2$ & $42.4 \pm 2.4$ \\
& $\mathrm{Y}$ & $12.5 \pm 3.5$ & $20.1 \pm 3.2$ & $23.7 \pm 3.5$ \\
D. maramus & $\mathrm{C}$ & $37.1 \pm 2.0$ & $41.7 \pm 2.2$ & $46.2 \pm 1.4$ \\
& $\mathrm{Y}$ & $3.6 \pm 1.3$ & $11.4 \pm 1.9$ & $18.0 \pm 1.8$ \\
C. famata & $\mathrm{C}$ & $40.4 \pm 1.4$ & $44.4 \pm 1.4$ & $46.6 \pm 1.4$ \\
& $\mathrm{Y}$ & $7.1 \pm 1.4$ & $14.0 \pm 2.8$ & $15.9 \pm 2.1$ \\
C. zeylanoides & $\mathrm{C}$ & $34.4 \pm 1.9$ & $39.6 \pm 2.0$ & $41.7 \pm 2.1$ \\
& $\mathrm{Y}$ & $2.1 \pm 1.0$ & $5.7 \pm 2.2$ & $8.8 \pm 2.3$ \\
H. burtonii & $\mathrm{C}$ & $35.4 \pm 2.2$ & $39.5 \pm 2.0$ & $41.9 \pm 2.1$ \\
& $\mathrm{Y}$ & $0.7 \pm 0.4$ & $5.6 \pm 1.8$ & $8.8 \pm 1.8$ \\
\hline
\end{tabular}

${ }^{\text {a }}$ Colony diameter is reported as mean \pm standard error.

Inhibitory activity against $P$. nordicum was not influenced by yeast co- or delayed inoculation (data not shown). A different inhibitory activity against $P$. nordicum was found among yeast species (Table 2): C. zeylanoides and $H$. burtonii showed the highest inhibition ( $86 \%$ and $88 \%$ respectively) and D. hansenii the lowest one (58\%).

Table 2. Effect of yeast species, salt presence in YPD medium and fungal inoculum concentrations over yeast inhibitory activity vs. P. nordicum after 14 days of incubation at $20{ }^{\circ} \mathrm{C}$. Least Square Means of \% inhibitory activity according to yeast species (YS), $P$. nordicum inoculum concentration $(\mathrm{PN})$, and $\mathrm{NaCl}$ presence in $\mathrm{YPD}(\mathrm{S})$ were reported ${ }^{\mathrm{a}}$.

\begin{tabular}{lll}
\hline Item & \% Inhibitory activity & $P$-value \\
\hline YS & & 0.000 \\
D. hansenii & $58.2 \mathrm{c}$ & \\
D. maramus & $75.9 \mathrm{~b}$ & \\
C. famata & $72.6 \mathrm{~b}$ & \\
C. zeylanoides & $85.9 \mathrm{a}$ & \\
H. burtonii & $87.9 \mathrm{a}$ & \\
& & \\
$\mathbf{P N}$ & & \\
$10^{2}$ conidia $/ \mathrm{mL}$ & $87.9 \mathrm{a}$ & \\
$10^{4}$ conidia $/ \mathrm{mL}$ & $73.2 \mathrm{~b}$ & \\
$10^{6}$ conidia $/ \mathrm{mL}$ & $67.1 \mathrm{~b}$ & \\
& & \\
$\mathbf{S}$ & & 0.000 \\
$0 \% \mathrm{NaCl}$ & $71.7 \mathrm{~b}$ & \\
$3 \% \mathrm{NaCl}$ & $80.5 \mathrm{a}$ & \\
& & 0.000 \\
Interaction $\mathrm{YS} \times \mathrm{S}$ & & 0.724 \\
Interaction $\mathrm{YS} \times \mathrm{PN}$ & & 0.803 \\
Interaction S $\times \mathrm{PN}$ & & \\
\hline
\end{tabular}

${ }^{a}$ different letters in the same column mean significant differences (Bonferroni multiple comparison test, $P<0.05$ ). 
Assayed yeast inhibitory activity was affected by the concentration of $P$. nordicum inoculum: the growth of colonies from the lowest inoculum concentration $\left(10^{2}\right.$ conidia $\left./ \mathrm{mL}\right)$ was the most inhibited by antagonistic yeasts; similar growth was observed in colonies grown $10^{4}$ and $10^{6}$ conidia/mL as inoculum.

Salt is the basic ingredient of dry-cured meat products and its influence over yeast biocontrol was tested by means of $\mathrm{NaCl}$ addition in YPD medium. The presence of $3 \% \mathrm{NaCl}$ increased $(P<0.05)$ the inhibitory activity of yeasts against $P$. nordicum, and a significant interaction between salt and yeast species has been found (Table 2).

As a consequence, the influence of salt over yeast inhibitory activity changed according to yeast species, as displayed in Figure 2. Salt enhanced significantly the inhibition exerted by the halophilic yeast $D$. hansenii against $P$. nordicum (70\% vs. 40\% in YPD with and without salt respectively).

Figure 2. Influence of $\mathrm{NaCl}(0 \%$ or $3 \%$ in YPD medium) on yeast inhibitory activity against $P$. nordicum (\% diameter reduction at 14 days of incubation at $20{ }^{\circ} \mathrm{C}$ ).

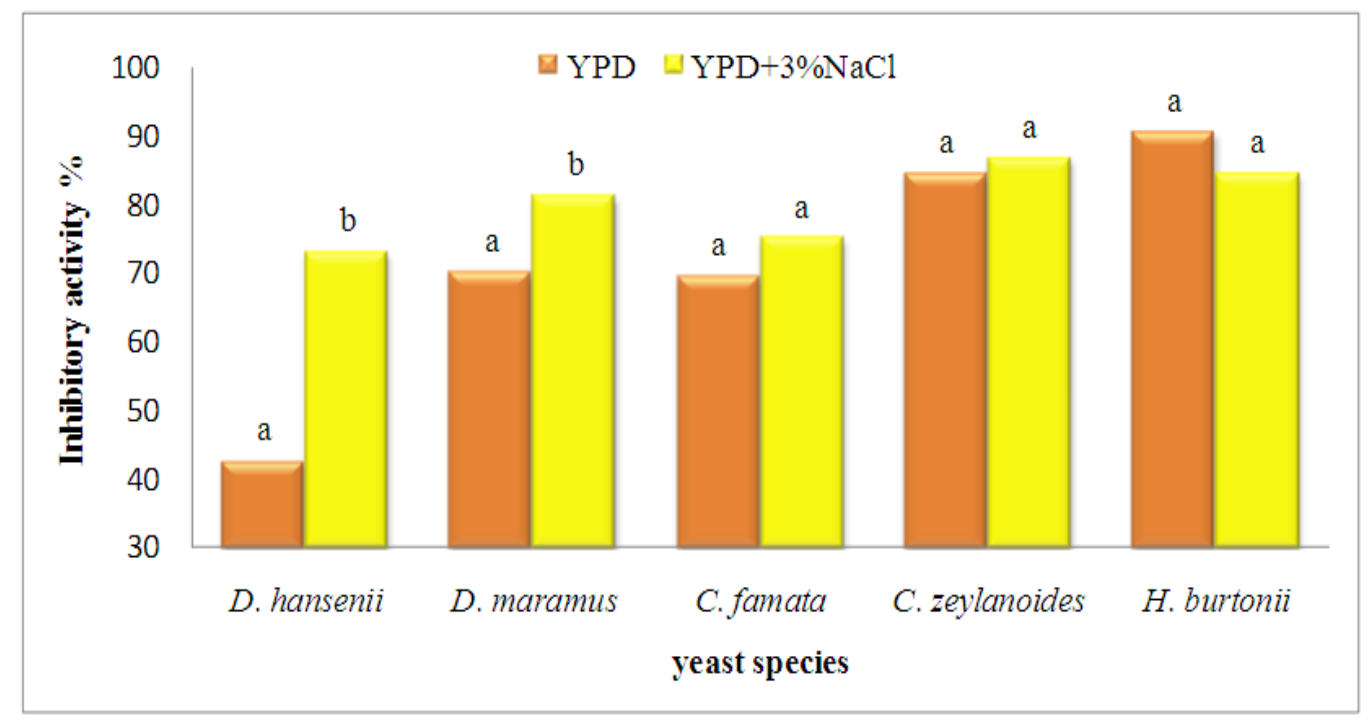

\subsection{OTA Production in Control and Yeast-Added Plates}

Ochratoxin A production by $P$. nordicum was quantified both in yeast-added and control plates after 14 days of incubation (Table 3): OTA values were grouped according to $P$. nordicum inoculum concentrations, and spanned in the range $<$ LOD $-5000 \mathrm{ppb}$. In control plates, OTA values associated to the lowest $P$. nordicum inoculum exceeded those found with higher inoculum concentrations. In plates with antagonist yeasts, featured by a sharp OTA reduction, the effect of fungal inoculum level was not so clear. 
Table 3. Mean, median and $95^{\text {th }}$ percentile production of ochratoxin A (OTA) (ppb) by $P$. nordicum in control and yeast-added plates after 14 days of incubation. OTA values were averaged over tested yeast strains.

\begin{tabular}{lcccc}
\hline & & \multicolumn{3}{c}{ OTA (ppb) } \\
\cline { 3 - 5 } & & Mean & Median & $\mathbf{9 5}^{\text {th }}$ percentile \\
\hline Control plates & $10^{2}$ & 2353 & 2518 & 4523 \\
three levels of $P$. nordicum inoculum & $10^{4}$ & 1652 & 1587 & 3429 \\
as conidia/mL & $10^{6}$ & 1064 & 1000 & 2432 \\
\hline Yeast-added plates & $10^{2}+\mathrm{Y}$ & 33.3 & 4.0 & 187 \\
three levels of $P$. nordicum inoculum as & $10^{4}+\mathrm{Y}$ & 35.2 & 4.0 & 138 \\
conidia/mL $+10^{8}$ cfu/mL yeasts $(\mathrm{Y})$ & $10^{6}+\mathrm{Y}$ & 42.7 & 7.5 & 179 \\
\hline
\end{tabular}

According to OTA value distribution, three percentile groups of equal frequency $(33.3 \%)$ were created and named high $(\mathrm{H})$, intermediate $(\mathrm{M})$ and low $(\mathrm{L})$ with reference to OTA content range (Table 4).

Table 4. Distribution (\%) of OTA amounts detected in control (C) and yeast-added (Y) plates into groups based on OTA percentile values with 3 cut points for equal groups $(33.3 \%)^{\mathrm{a}}$.

\begin{tabular}{c|ccc}
\hline Yeast species & OTA & C & Y \\
\hline D. maramus & $\mathrm{L}$ & 0 & 69 \\
& $\mathrm{M}$ & 29 & 31 \\
& $\mathrm{H}$ & 71 & 0 \\
\cline { 2 - 4 } D. hansenii & $\mathrm{L}$ & 0 & 47 \\
& $\mathrm{M}$ & 35 & 53 \\
C. famata & $\mathrm{H}$ & 65 & 0 \\
\cline { 2 - 4 } & $\mathrm{L}$ & 0 & 58 \\
& $\mathrm{M}$ & 40 & 42 \\
C. zeylanoides & $\mathrm{H}$ & 60 & 0 \\
\cline { 2 - 4 } & $\mathrm{L}$ & 0 & 75 \\
& $\mathrm{M}$ & 35 & 25 \\
H. burtonii & $\mathrm{H}$ & 65 & 0 \\
\cline { 2 - 4 } & $\mathrm{L}$ & 0 & 86 \\
& $\mathrm{M}$ & 33 & 14 \\
& $\mathrm{H}$ & 67 & 0 \\
\hline \multirow{5}{*}{ LOD $-27 \mathrm{ppb}$ Intermediate (M) range $=28-911 \mathrm{ppb}$ High (H) range $=912-4697 \mathrm{ppb}}$.
\end{tabular}

A comparison was carried out between control and yeast-added plates to compare percentage distributions between groups ( $\chi 2$ statistic). The yeast inhibitory activity over OTA production was significant $(P<0.001)$ : control plates were mostly allocated to $\mathrm{H}$ group, the yeast-added ones to $\mathrm{L}$ group, while the frequencies of control and treated plates in M group were similar.

The effect of yeast species over OTA distribution in H, M and L groups is reported in Table 5: (i) the frequency distribution of $H$. burtonii differed from D. maramus, C. famata and D. hansenii; 
(ii) C. zeylanoides differed from C. famata and D. hansenii; (iii) D. maramus differed from D. hansenii.

Table 5. $P$ values ( $\chi 2$ statistic, $P<0.05$ means significant difference) for the effect of yeast species on OTA distribution into groups reported in Table 4.

\begin{tabular}{lcccc}
\hline & D. maramus & C. famata & C. zeylanoides & H. burtonii \\
\hline D. hansenii & 0.000 & 0.310 & 0.000 & 0.000 \\
D. maramus & & 0.092 & 0.260 & 0.032 \\
C. famata & & & 0.006 & 0.000 \\
C. zeylanoides & & & & 0.135 \\
\hline
\end{tabular}

Ochratoxin A values detected in control and yeast-treated plates were split with reference to salt presence in YPD medium (Figure 3). In control plates, salt presence favored OTA production (Figure 3a), while in yeast-added plates, an opposite result was evidenced (Figure 3b).

Figure 3. (a) Ochratoxin A (OTA) distribution in control and yeast treated plates, clustered according to salt presence in growing media (YPD and YPD $+3 \% \mathrm{NaCl}$ ); (b) Magnification of yeast treated plate box plots.

(a)

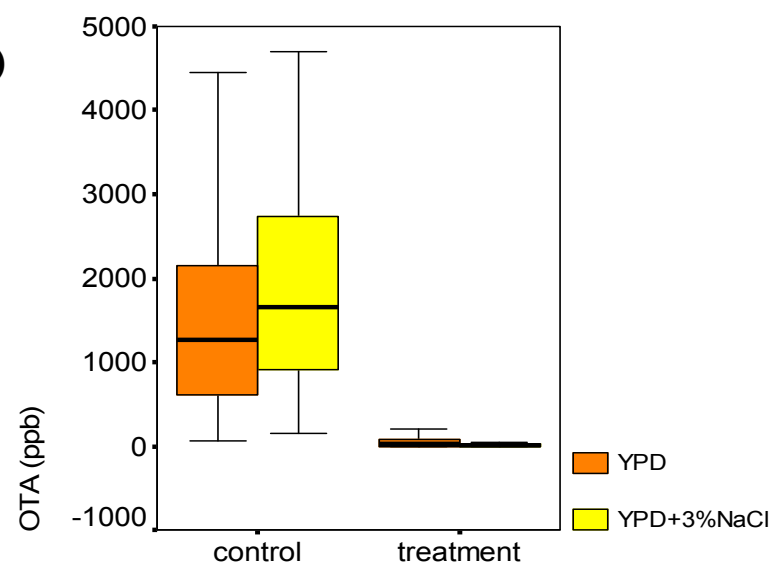

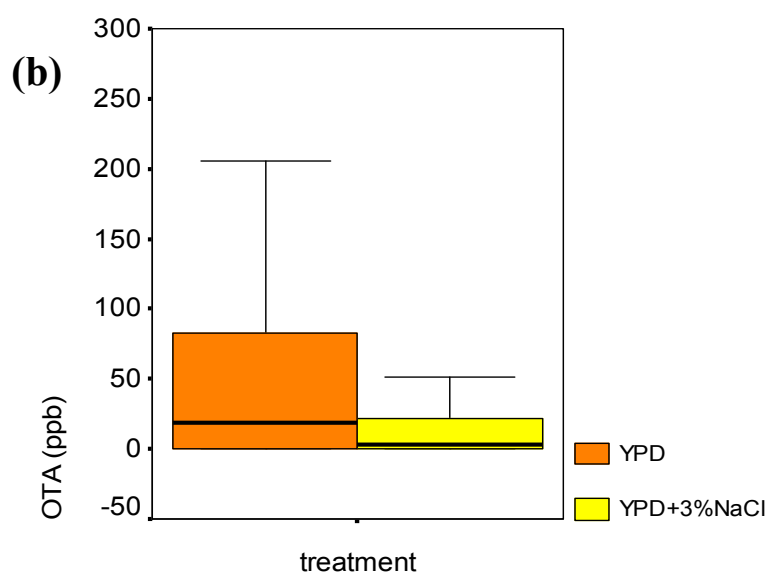

OTA analysis in spiked control and yeast-added plates had the same $\%$ recovery, showing that yeast presence did not affect OTA extraction from the growing medium (Table 6).

Table 6. Detected amount and \% recovery of ochratoxin A (OTA) in plates without $(\mathrm{N})$ or with $10^{8} \mathrm{cfu} / \mathrm{mL}$ yeasts $(\mathrm{Y})$. Each plate was spiked with 500 ppb OTA. OTA values are reported as mean \pm standard deviation.

\begin{tabular}{cccc}
\hline medium & Yeasts (cfu/mL) & OTA (ppb) & Recovery (\%) \\
\hline \multirow{2}{*}{ YPD } & N & $405 \pm 25$ & 81 \\
& Y & $375 \pm 17$ & 75 \\
\multirow{2}{*}{ YPD $+3 \% \mathrm{NaCl}$} & $\mathrm{N}$ & $390 \pm 15$ & 78 \\
& $\mathrm{Y}$ & $425 \pm 13$ & 85 \\
\hline
\end{tabular}




\section{Discussion}

The microbial community growing on dehydrated surface of dry-cured ham during the maturing phase is dominated by several species of yeasts and moulds [15,34]; the former population, is present from early processing steps, while the latter becomes dominating during maturation [4]. The efficacy of native yeasts as biocontrol agents is questionable because moulds frequently colonize ham surface in the presence of yeasts [3].

Information on the antagonistic activities of yeasts isolated from dry-cured meat products against toxigenic fungi is scarce [35]: recent study differentiated yeasts isolated from dry-cured ham according to their inhibitory effect in vitro against an OTA-producing P. nordicum strain [19]. Although the mechanisms underlying the observed inhibition were not yet investigated, it is likely that the presence of a high yeast population $\left(10^{8} \mathrm{cfu} / \mathrm{mL}\right)$ may restrict the availability of nutrients and sites for colonization, essential for the germination of mould spores [36]. Significant differences were found among assayed yeasts in terms of \% inhibitory activity, being $H$. burtonii and C. zeylanoides the most, and $D$. hansenii the least effective in inhibiting $P$. nordicum growth.

D. hansenii is the predominant species in dry-cured ham isolates during processing [15,17], but this predominance becomes more remarkable in fully matured products. The high occurrence of $D$. hansenii in dry-cured meat products is most probably due to its moderately halophilic properties, accounting for its optimal growth at 3-5\% salt [37]. A recent study demonstrated that a higher number of $D$. hansenii strains isolated from dry-cured meat products were able to growth up to $15 \% \mathrm{NaCl}$ if compared to C. zeylanoides [16]. However, the lowest inhibitory activity exerted in the present study by $D$. hansenii against $P$. nordicum could be predictive of less effectiveness of this yeast as biocontrol agent.

The occurrence of $C$. zeylanoides was found to decrease from early to late processing steps [16,17]: in Italian dry-cured hams, though isolated up to final maturation, the incidence on muscle surface was lower during maturing phases than at the beginning of processing [15]. So, even if in vitro tested strains of $C$. zeylanoides highly inhibited $P$. nordicum, under dry-curing plant conditions (fluctuation of temperature, relative humidity, air circulation, decrease of water availability in surface muscle), C. zeylanoides, having been found to fail in maintaining high populations in matured dry-cured ham, could have less ecological fitness than $D$. hansenii. Furthermore, $C$. zeylanoides was included among emerging pathogenic yeasts [18] and considered unsuitable as biocontrol agent.

Hyphopichia burtonii, referred to as "yeast-like fungi", was isolated from dry-cured hams after surface fat application during maturation. The yeast was probably introduced by the rice flour mixed with the spreadable pork fat (sugna) used at mid maturing to prevent excessive dehydration of ham surface [15]. It was reported as capable of inhibiting the spore germination of $P$. verrucosum and the growth of $P$. roquefortii [22,38], and the interest in this species is confirmed by the performance against $P$. nordicum showed in the present study. Otherwise, the attribution of $H$. burtonii to dry-cured ham native yeasts is questionable and its potential as biocontrol agent against $P$. nordicum should be tested in ripening plant conditions, before sugna application.

Debaryomyces maramus and $C$. famata (the anamorphic form of $D$. hansenii) were isolated throughout the processing of Parma ham and other traditional Greek and Spanish dry-cured products $[15,39,40]$, even less frequently than $D$. hansenii and C. zeylanoides. In the case of orange fruits, a C. famata population $\left(10^{8} \mathrm{cfu} / \mathrm{mL}\right)$ gave a successful biocontrol toward Penicillium digitatum [41] in the present 
study $C$. famata exerted lower inhibition against $P$. nordicum than $H$. burtonii and C. zeylanoides, and an higher inhibition than $D$. hansenii. Penicillium contamination in cured meat production facilities and products was found to be affected by a large variability [4,42]: accordingly, the biocontrol test was performed using inoculation levels of $P$. nordicum corresponding to $10^{2}, 10^{4}, 10^{6}$ conidia $/ \mathrm{mL}$. Yeast inhibitory activity was affected by fungal concentration: at the lowest inoculum level, yeast biocontrol was more effective $(P<0.05)$, showing that the concentration of the mould is a key factor for yeast effectiveness. As a consequence, in future in vivo applications of antagonistic yeasts for dry-cured ham biocontrol, it will be important to keep the population of contaminating moulds as low as possible, in agreement with processing procedures for high quality dry-cured meat products aimed at this specific target [43]. Among yeast dominant species isolated from dry-cured hams, the tolerance to $\mathrm{NaCl}$ has been evidenced [16,19], a property enabling autochthonous yeasts to colonize and prevail in dry-cured ham surface microflora: this halotolerance is in agreement with the positive effect of $3 \% \mathrm{NaCl}$ presence upon yeast inhibition activities. The same tolerance was recently demonstrated also for $P$. nordicum, capable of growing and producing OTA in dry-cured pork samples in the presence of 5\% $\mathrm{NaCl}$ and $0.90 \mathrm{a}_{\mathrm{w}}$ [14]. A significant interaction "yeast $\times$ salt" was found and displayed in Figure 2. The inhibitory activity was significantly enhanced by $3 \% \mathrm{NaCl}$ only for Debaryomyces spp., mostly in the case of $D$. hansenii.

The tested strains of $D$. hansenii gave, on average, the least inhibition among tested yeasts, but, thanks to its halophilic aptitude [37], may be that $\mathrm{NaCl}$ had a key role in inhibition expression. Some authors found that $D$. hansenii was able to synthesize toxic proteins with killer capacity against sensitive strains, but the lethal activity of these toxins was demonstrated or increased only in the presence of $\mathrm{NaCl}[44,45]$. Other tested yeasts did not show any difference due to $\mathrm{NaCl}$ presence in the medium.

The biocontrol by means of antagonistic yeasts is a potential strategy both against toxigenic moulds and to prevent or minimize mycotoxin production. In this study, the production of OTA was examined when $P$. nordicum was in pure culture (control plates) or cultured with yeast strains (yeast-added plates). The temperature of the biocontrol test $\left(20^{\circ} \mathrm{C}\right)$ was previously found suitable for OTA high production in dry-cured pork model systems [14]. In the presence of yeasts, the growth inhibition of P. nordicum correlated with the sharp reduction of OTA (Table 3). In the above-mentioned test conditions, the competition for nutrients and space could be the mechanism inhibiting both P. nordicum growth and secondary metabolism, including OTA production [30]. In yeast-added plates, an average tendency of OTA production to increase according to $P$. nordicum inoculum concentration was found. In control plates, when the $P$. nordicum inoculum is low $\left(10^{2}\right.$ conidia $\left./ \mathrm{mL}\right)$, the nutrients not required for fungal growth could be used for OTA biosynthesis. Ochratoxin A frequency distribution into groups of equal frequency $(33.3 \%) \mathrm{L}, \mathrm{M}$ and $\mathrm{H}$ changed according to yeast presence and species. Treated plates corresponded to low (L) or intermediate (M) OTA category production, while control plates fell mostly in high $(\mathrm{H})$ category. In agreement with inhibitory activity values reported in Table 2 , D. hansenii gave OTA value frequency different from H. burtonii, C. zeylanoides and D. maramus, $C$. famata differed from $H$. burtonii and C. zeylanoides and D. maramus from $H$. burtonii. These results suggested that the same mechanism of biocontrol was effective against both $P$. nordicum growth and OTA production; otherwise, other studies reported that although the growth of spoilage fungi is inhibited by biocontrol of antagonistic yeasts, their metabolic activities are not necessarily reduced $[21,36]$. The 
effect of $3 \% \mathrm{NaCl}$ in control and yeast-added plates was examined with reference to OTA production (Figure 3): in control plates with $\mathrm{NaCl}$, OTA reached higher values than in without-salt counterparts, suggesting a salt-stress related increase in mycotoxin biosynthesis. Otherwise, the presence of $\mathrm{NaCl}$ improved yeast biocontrol, enabling an almost total inhibition of OTA production. This finding is in agreement with the " $\mathrm{NaCl}$ " positive effect against $P$. nordicum growth in yeast-added plates (Table 2). Yeasts were also reported for decreasing OTA content by adsorbption on the external and internal part of the cells, sequestering the toxin or even degrading it [46]; the cell wall has a chemical composition that varies from yeast to yeast, regulating the adsorption/non-adsorption activity of yeasts [47]. The assay made to check OTA stability and recovery in control and yeast-added plates (Table 6), shows that OTA was stable in YPD medium with and without $\mathrm{NaCl}$, and OTA recovery was not affected by yeast presence. In this respect, the sharp decrease of OTA in treated plates cannot be ascribed to degradation or adsorption by yeasts. Moreover, even in the case of adsorption, the usage of methanol for extraction, by denaturing yeast parietal protein, allowed OTA to be recovered ( $75-85 \%$ recovery range).

\section{Conclusions}

This study demonstrated that selected strains of yeasts isolated from dry-cured ham, exerted in vitro inhibition activity against $P$. nordicum cultured in the presence of high yeast population $\left(10^{8} \mathrm{cfu} / \mathrm{mL}\right)$. The inhibition was effective against both fungal growth and OTA production, and was significantly influenced by yeast species, level of fungal contamination and $\mathrm{NaCl}$ presence in culture medium.

$\mathrm{NaCl}$ promoted a significant increase of biocontrol activity, favoring the most halophilic yeast strains such as $D$. hansenii, but other species exerted a more efficient control on $P$. nordicum growth and OTA synthesis. The antagonistic activity of tested yeasts was negatively affected by increasing levels of fungal contamination. Assayed yeasts could be effective biocontrol agents for dry-cured meat products, if capable of quickly growing and long lasting. In this respect, future works will be aimed to test the efficacy of different yeasts species in ripening plants, to optimize the inoculum distribution and to achieve suitable conditions for yeast stable and efficient colonization of product surface.

\section{References}

1. Martin, M.; Cordoba, J.J.; Aranda, E.; Cordoba, M.G.; Asensio, M.A. Contribution of selected fungal population to the volatile compounds of dry -cured ham. Int. J. Food Microbiol. 2006, 110, $8-13$.

2. Andrade, M.J.; Cordoba, J.J.; Sánchez, B.; Casado, E.M.; Rodríguez, M. Evaluation and selection of yeasts isolated from dry-cured Iberian ham by their volatile compound production. Food Chem. 2009, 113, 457-463.

3. Spotti, E.; Berni, E.; Cacchioli, C. Characteristics and Applications of Molds. In Meat Biotechnology, 1st ed.; Toldrá, F., Ed.; Springer: New York, NY, USA, 2008; pp. 181-195.

4. Asefa, D.T.; Kure, C.F.; Gjerde, R.O.; Omer, M.K.; Langsrud, S.; Nesbakken, T.; Skaar, I. Fungal growth pattern, sources and factors of mould contamination in dry-cured meat production process. Int. J. Food Microbiol. 2010, 140, 131-135. 
5. Battilani, P.; Pietri, A.; Giorni, P.; Formenti, S.; Bertuzzi, T.; Toscani, T.; Virgili, R.; Kozakiewicz, Z. Penicillium population in dry-cured ham manufacturing plants. J. Food Prot. 2007, 70, 975-980.

6. Nunez, F.; Rodriguez, M.M.; Bermudez, M.E.; Cordoba, J.J.; Asensio, M.A. Composition and toxigenic potential of the mould population on dry-cured Iberian ham. Int. J. Food Microbiol. 1996, 32, 185-197.

7. Comi, G.; Orlic, S.; Redzepovic, S.; Urso, R.; Iacumin, L. Moulds isolated from Istrian dried ham at the pre-ripening and ripening level. Int. J. Food Microbiol. 2004, 96, 29-34.

8. Wang, X.; Ma, P.; Jiang, D.; Peng, Q.; Yang, H. The natural microflora of Xuanwei ham and the no-mouldy ham production. J. Food Eng. 2006, 77, 103-111.

9. Castellari, C.; Quadrelli, A.M.; Laich, F. Surface mycobiota on Argentinean dry fermented sausages. Int. J. Food Microbiol. 2010, 142, 149-155.

10. Larsen, T.O.; Svendsen, A.; Smedsgaard, J. Biochemical characterization of ochratoxin A-producing strains of the genus Penicillium. Appl. Environ. Microbiol. 2001, 67, 3630-3635.

11. Pfohl-Leszkowicz, A. Ochratoxin A and aristolochic acid involvement in nephropathies and associated urothelial tract tumors. Arh. Hig. Rada Toksikol. 2009, 60, 465-483.

12. Frisvad, J.C.; Samson, R.A. Polyphasic taxonomy of Penicillium subgenus Penicillium: A guide to identification of food and air-borne terverticillate Penicillia and their mycotoxins. Stud. Mycol. 2004, 49, 1-173.

13. Pietri, A.; Bertuzzi, T.; Gualla, A.; Piva, G. Occurrence of ochratoxin A in raw ham muscles and in pork products from northern Italy. Ital. J. Food Sci. 2006, 18, 1-8.

14. Battilani, P.; Formenti, S.; Toscani, T.; Virgili, R. Influence of abiotic parameters on ochratoxin A production by Penicillium nordicum strain in dry-cured meat model systems. Food Control 2010, 21, 1739-1744.

15. Simoncini, N.; Rotelli, D.; Virgili, R.; Quintavalla, S. Dynamics and characterization of yeasts during ripening of typical Italian dry-cured ham. Food Microbiol. 2007, 24, 577-584.

16. Asefa, D.T.; Møretrø, T.; Gjerde, R.O.; Langsrud, S.; Kure, C.F.; Sidhu, M.S.; Nesbakken, T.; Skaar, I. Yeast diversity and dynamics in the production processes of Norwegian dry-cured meat products. Int. J. Food Microbiol. 2009, 133, 135-140.

17. Nunez, F.; Rodriguez, M.M.; Cordoba, J.J.; Bermudez, M.E.; Asensio, M.A. Yeast population during ripening of dry-cured Iberian ham. Int. J. Food Microbiol. 1996, 29, 271-280.

18. Levenson, D.; Pfaller, M.A.; Smith, M.A.; Hollis, R.; Gerarden, T.; Tucci, C.B.; Isenberg, H.D. Candida zeylanoides: an opportunistic yeast. J. Clin. Microbiol. 1991, 29, 1689-1692.

19. Simoncini, N.; Virgili, R.; Quintavalla, S.; Formenti, S.; Battilani, P. Biotypization of autochthonous yeasts of dry-cured meat products. Ind. Conserve 2009, 84, 107-114.

20. Pinna, A.; Quintavalla, S.; Simoncini, N.; Toscani, T.; Virgili, R. Volatile organic compounds of a ham-like model system inoculated with authoctonous yeasts isolated from typical hams. Ind. Conserve 2009, 84, 91-103.

21. Petersson, S.; Hansen, M.W.; Axberg, K.; Hult, K.; Schnürer, J. Ochratoxin A accumulation in cultures of Penicillium verrucosum with the antagonistic yeast Pichia anomala and Saccharomyces cerevisiae. Mycol. Res. 1998, 102, 1003-1008. 
22. Druvefors, U.A.; Schnürer, J. Mold-inhibitory activity of different yeast species during airtight storage of wheat grain. FEMS Yeast Res. 2005, 5, 373-378.

23. Masoud, W.; Kaltoft, C.H. The effects of yeasts involved in the fermentation of Coffea arabica in East Africa on growth and ochratoxin A (OTA) production by Aspergillus ochraceus. Int. J. Food Microbiol. 2006, 106, 229-234.

24. Guinebretiere, M.H.; Nguyen-The, C.; Morrison, N.; Reich, M.; Nicot, P. Isolation and characterization of antagonists for the biocontrol of the postharvest wound pathogen Botrytis cinerea on strawberry fruits. J. Food Prot. 2000, 3, 386-394.

25. Suzzi, G.; Romano, P.; Ponti, I.; Montuschi, C. Natural wine yeasts as biocontrol agents. J. Appl. Bacteriol. 1995, 78, 304-308.

26. Liu, S.Q.; Tsao, M. Biocontrol of dairy moulds by antagonistic dairy yeast Debaryomyces hansenii in yoghurt and cheese at elevated temperatures. Food Control 2009, 20, 852-855.

27. Sánchez-Molinero, F.; Arnau, J. Effect of the inoculation of a starter culture and vacuum packaging (during resting stage) on the appearance and some microbiological and physicochemical parameters of dry-cured ham. Meat Sci. 2008, 79, 29-38.

28. Kurtzman, C.P.; Robnett, C.J. Identification and phylogeny of ascomycetous yeasts from analysis of nuclear large-subunit (26S) ribosomal DNA partial sequences. Antoine van Leeuwenhoek 1997, 73, 331-371.

29. Bogs, C.; Battilani, P.; Geisen, R. Development of a molecular detection and differentiation system for ochratoxin A producing Penicillium species and its application to analyse the occurrence of P. nordicum in cured meats. Int. J. Food Microbiol. 2006, 107, 39-47.

30. Bleve, G.; Grieco, F.; Logrieco, A.; Visconti, A. Isolation of epiphytic yeasts with potential for biocontrol of Aspergillus carbonarius and A. niger on grape. Int. J. Food Microbiol. 2006, 108, 204-209.

31. Lima, G.; Arru, S.; De Curtis, F.; Arras, G. Influence of antagonistic, host fruit and pathogen on the biological control of postharvest fungal diseases by yeasts. J. Ind. Microbiol. Biotechnol. 1999, 23, 223-229.

32. Bragulat, M.R.; Abarca, M.L.; Cabañes, F.J. An easy screening method for fungi producing ochratoxin A in pure culture. Int. J. Food Microbiol. 2001, 71, 139-144.

33. Toscani, T.; Moseriti, A.; Dossena, A.; Dall'Asta, C.; Simoncini, N.; Virgili, R. Determination of ochratoxin A in dry-cured meat products by HPLC-FLD quantitative methods. J. Chromatogr. B 2007, 855, 242-248.

34. Asefa, D.T.; Gjerde, R.O.; Sidhu, M.S.; Langsrud, S.; Kure, C.F.; Nesbakken, T.; Skaar, I. Moulds contaminants on Norwegian dry-cured meat products. Int. J. Food Microbiol. 2009, 128, 435-439.

35. Spotti, E.; Berni, E.; Cacchioli, C.; Simoncini, N.; Quintavalla, S. Growth and antagonistic activity of Hyphopichia burtonii against other fungal species frequently found on meat products during maturation. Ind. Conserve 2009, 84, 11-22.

36. Björnberg, A.; Schnürer, J. Inhibition of the growth of the grain-storage molds in vitro by the yeast Pichia anomala (Hansen) Kurtzman. Can. J. Microbiol. 1993, 39, 623-628.

37. Breuer, U.; Harms, H. Debaryomyces hansenii-an extremophilic yeast with biotechnological potential. Yeast 2006, 23, 415-437. 
38. Ramakrishna, N.; Lacey, J.; Smith, J.E. Colonization of barley grain by Penicillium verrucosum and Ochratoxin A formation in the presence of competing fungi. J. Food Prot. 1996, 59, 1311-1317.

39. Metaxopoulos, J.; Stavropoulos, S.; Kakouri, A.; Samelis, J. Yeasts isolated from traditional Greek dry salami. Ital. J. Food Sci. 1996, 1, 25-32.

40. Monte, E.; Villanueva, J.R.; Domìnguez, A. Fungal profiles of Spanish country-cured hams. Int. J. Food Microbiol. 1986, 3, 355-359.

41. Arras, G. Mode of action of an isolate of Candida famata in biological control of Penicillium digitatum in orange fruits. Postharvest Biol. Technol. 1996, 8, 191-198.

42. Sonjak, S.; Ličen, M.; Frisvad, J.C.; Gunde-Cimerman, N. The mycobiota of three dry-cured meat products from Slovenia. Food Microbiol. 2011, 28, 373-376.

43. Asefa, D.; Kure, C.F.; Gjerde, R.O.; Langsrud, S.; Omer, M.O.; Nesbakken, T.; Skaar, I. A HACCP plan for mycotoxigenic hazards associated with dry-cured meat production processes. Food Control 2010, 22, 831-837.

44. Llorente, P.; Marquina, D.; Santos, A.; Peinado, J.M.; Spencer-Martins, I. Effect of salt on the killer phenotype of yeasts from olive brines. Appl. Environ. Microbiol. 1997, 63, 1165-1167.

45. Marquinia, D.; Barroso, J.; Santos, A.; Peinado, J.M. Production and characteristics of Debaryomyces hansenii killer toxin. Microbiol. Res. 2001, 156, 387-391.

46. Patharajan, S.; Reddy, K.R.N.; Spadaro, D.; Lore, A.; Gullino, M.L.; Garibaldi, A.; Karthikeyan, V. Potential of yeast antagonists on in vitro biodegradation of ochratoxin A. Food Control 2011, 22, 290-296.

47. Caridi, A. New perspectives in safety and quality enhancement of wine through selection of yeasts based on the parietal adsorption activity. Int. J. Food Microbiol. 2007, 120, 167-172.

(C) 2012 by the authors; licensee MDPI, Basel, Switzerland. This article is an open access article distributed under the terms and conditions of the Creative Commons Attribution license (http://creativecommons.org/licenses/by/3.0/). 